\title{
El modernismo como proceso literario
}

\author{
Ricardo Ferrada $A^{*}$
}

\section{Resumen}

La extensa bibliografía que existe sobre el modernismo abre múltiples vías de estudio y análisis, las cuales manifiestan su condición de pluralidad en formas expresivas y el simultaneísmo con que emerge en el espacio geográfico de habla hispana.

La instancia que significa investigarlo nos pone ante un campo de estudios que, en lo global, se somete a una doble modalidad, esto es, el diálogo entre la historia literaria y la historia cultural, una línea de trabajo que se sitúa más allá de una forma clausular de comprender un hecho literario.

La intención de este artículo, entonces, consiste en observar el modo en que se asumió el proyecto modernista; adicionalmente, otra línea de sentido propone la idea de que el modernismo prefigura formas expresivas asociadas a la vanguardia poética.

Palabras clave: modernismo, proceso literario, poética, vanguardia.

\section{Abstract}

The extensive bibliography that exists about modernism opens different ways of research and analysis. Thus, it gives account of the condition of a plurality and simultaneism expression forms, that emerge within the spanish speaking geographical area.

The instance of doing research about modernism, since a global view, places us in front of a dual mode, that is, the dialogue between the literary and the cultural history, a working line which is beyond a clause way of understanding. a literary fact.

Thus, the intention of this article is to observe how the modernist project was assumed. In addition, a different line of meaning suggest the idea that modernism shaped expression ways associated with the vanguard poetry.

Key words: modernism, litterary process, poetry, vanguard.

* Doctor en Estudios Americanos. Académico de la Universidad Católica Silva Henríquez. rferrada@vtr.net 
La torre de marfil tentó mi anhelo: quise encerrarme dentro de mí mismo, y tuve hambre de espacio y sed de cielo desde las sombras de mi propio abismo

Rubén Darío

\section{Presentación}

Entre las consideraciones iniciales que debemos manifestar, resulta insoslayable aludir el que frente a un fenómeno literario como es el modernismo, la bibliografía que existe sobre el tema y las múltiples vías de su estudio y análisis, habitualmente convergen en un aspecto esencial: su condición de pluralidad en formas expresivas y el simultaneísmo con que emerge en el espacio geográfico hispanoamericano.

No obstante la certeza anterior con su implícita invariabilidad, nuestro interés apunta a relevar una variante en ese ámbito, esto es, su condición de un movimiento sometido a sus propias tensiones internas, a lo que se agregan los alcances impensados de su desarrollo. En tal sentido, creemos que la historia que lo explica y la dinámica que asumieron sus estrategias formales se articulan con la mirada de quienes impulsaron su proyecto, que si fue determinado por las condiciones de producción, estas se manifestarán extrañamente desde un fondo contradiscursivo hacia su época. Estimamos que esto aporta en su examen y recepción para asimilarla a una sensibilidad estética.

La instancia que significa estudiar hoy el modernismo literario, constituye, desde tal perspectiva, entrar en un campo de estudios que, en lo global, se somete a una doble modalidad, al enfrentarnos con una línea de trabajo que configura una suerte de diálogo entre la historia literaria y la historia cultural, una línea de trabajo que se sitúa más allá de una 
forma clausular de comprender un hecho literario, sustentada en la autosuficiencia de la obra'.

La idea de proceso en el contexto de la temática enunciada, entonces, se inscribe en el interés de examinar la forma canonizada de un movimiento, que en su dimensión de dualidad (es decir, literaria y cultural), ofrece distintas lecturas en su recepción. Creemos que su cuestionamiento de inicio significó interpretar las obras primeras como un discurso alterado, un discurso ajeno a América; en este punto, al observar la universalidad que impulsaba el proyecto, esta opera, paradojalmente, en un momento en el cual se gestaba la conciencia de identidad nacional y continental (segunda mitad del siglo XIX), y donde la expresión literaria formó parte del mismo fenómeno, esto es, una literatura nacional y la expresión americana de una manera en que los escritores construyen su imaginario.

Desde otro nivel, el momento de proceso inaugurador experimentado por el modernismo, su puesta en vigencia, en la terminología generacional, su posterior desarrollo y el fin de ese mismo proceso, pensamos, se resiste a un estudio uniformador. En relación con lo anterior, por ejemplo, si bien es cierto que existe una estética modernista, cuya materialidad son textos, obras, sus múltiples variaciones expresivas no alcanzan a conformar el absoluto que sus propios autores buscaban. Este es un punto clave, pues dadas las diversas orientaciones formales, vemos en algunos escritores la presencia de componentes de lenguaje literario que anuncian la vanguardia, en consecuencia, fue un proyecto que excedió su propia temporalidad. Esto, creemos, sin duda afecta la experiencia de recepción, particularmente el panorama de la poesía hispanoamericana hacia comienzos del siglo XX.

La intención de este artículo, entonces, consiste en observar una zona de problemas, esto es, el modo en que se asumió el proyecto modernista; adicionalmente, otra línea de sentido nos lleva a revisar la concepción del texto literario, en orden a establecer la pertinencia de nuestro planteamiento: en su proceso, el modernismo prefigura formas expresivas asociadas a la vanguardia poética.

Ciertamente, este es un trabajo que aborda un fenómeno amplio y complejo, de modo que antes bien abre una discusión sobre un aspecto que merece ampliarse y, además, observar las particularidades del caso. Es por ello que el acercamiento a obras y autores que hacemos aquí,

1 Es necesario acotar que esta idea tiene el componente teórico proveniente de Hans Robert Jauss y la estética de la recepción. Ver: Hans Robert Jauss (1987; 2001): “Historia de la literatura como una provocación a la ciencia literaria", en En busca del texto, México: Unam, Dietrich Rall, compilador; José Antonio Mayoral (comp. 1987). Estética de la recepción. Madrid: Arco/Libros. 
se enmarca en el contexto de demostrar o ejemplificar en función de nuestra premisa de lectura.

\section{La conciencia modernista}

En el decir de Octavio Paz, "el modernismo fue la respuesta al positivismo, la crítica de la sensibilidad y el corazón -también de los nervios-el empirismo y el cientismo positivista. En este sentido su función histórica fue semejante a la de la reacción romántica en el alba del siglo XIX. EI modernismo fue nuestro verdadero romanticismo...." (Paz, 1984: 128). Esta certera afirmación nos enfrenta a un modo de interpretar un periodo y cómo se constituyen los medios expresivos que lo manifiestan, asimismo, casi de forma inevitable, una perspectiva para comprender un fenómeno que modificó toda nuestra cultura a fines del siglo XIX, con proyecciones insospechadas con respecto a su origen.

Tal manera de comprender (o autocomprenderse), decimos, pone en juego una conciencia crítica y una sensibilidad, donde la posición distanciada nos sitúa no sólo ante el marco temporal de un fenómeno estético, sino que, además, a una imagen de sociedad. Sobre este punto es importante señalar que existe una visión interior de ese momento, manifestada por los creadores que impulsaron el periodo, visión que ya da cuenta de un proceso diferenciador y liberador en sentido amplio, en cuanto implicó soltar y desplazarse de horizonte cultural; en la práctica, asumir como referencia no la inmediata raíz española, sino el nuevo modelo francés.

En un contexto donde se vivía la consolidación de la nacionalidad en muchos países de nuestro continente, la visión interior del modernismo, es decir, la voz de sus propios gestores, asumió una postura y un discurso intencionalmente otro y distinto; por lo mismo, constituyó un modo de alteridad que impactó socialmente, generando de esa manera la idea de un pensamiento y una sensibilidad, asentados en una estética discontinua y a veces caótica, falta de un eje uniformador, asumida de modo consciente si seguimos a Darío, "porque proclamando, como proclamo, una estética acrática, la imposición de un modelo o de un código implicaría una contradicción" (Darío, 1978: 9).

Desde su contrapartida, la visión exterior tensiona aún más la fuerza de esa conciencia crítica y estética, si se piensa que en ese juicio de "acrática" opera una imagen conjetural o especulativa y un desafío para (re)construir ese discurso estético que remite al pensamiento anarquista europeo. Así, mediante situaciones y fenómenos cuya suma nos resulta ajena, definimos la propia identidad literaria: nos vemos, si no literal- 
mente, a lo menos resonando en la amplitud de la (im)pertenencia a una tradición intelectual, que resitúa nuestra autoimagen de cultura. Este hecho casi de metalenguaje fue sospechado en distintos niveles por los modernistas.

Lo que queremos decir, en el fondo, es que si el fenómeno llamado modernismo se constituyó como ruptura y como aprobación de formas literarias y estéticas que fueron vistas como extranjerizantes, esa misma crítica u observación nace desde propuestas de pensamiento cuyo origen, también, proviene desde lo externo o, si se quiere, operan como modelos que diseñan una orientación social y un modelo de sociedad que se discute: el pasado orden hispánico. La consecuencia fue que ese modernismo posibilitó una apertura a la discusión y, tal vez más importante, abrió a nuestros escritores espacios y zonas inexploradas en nuestro idioma y a nuestra geografía, a la vez que universalizó la imagen de nuestro propio continente.

La conciencia modernista tendrá, entonces, la suficiente plasticidad para recoger medios expresivos de diversos matices: versificación, cromatismo verbal, ritmos, temáticas, símbolos e imágenes míticas provenientes de la cultura oriental, también del mundo afroamericano. Al reverso de las formas, hubo un fondo de temas y tensiones poéticas que cada autor fue capaz de crear, desde su espacio lírico y geográfico, textos que constituyeron una visión de la realidad y, adicionalmente, una perspectiva sobre el hombre, a partir de su diferenciación respecto de la sociedad, donde el artista resultó el mayormente afectado, (recuérdese el cuento "El rey burgués"), por cuanto fue el más diferente en su búsqueda del amor a lo absoluto de la belleza, según las palabras que Darío expresa en el Prefacio a sus Cantos de vida y esperanza (1905).

El efecto último de esa construcción de lenguaje, en definitiva, establecerá no sólo la emergencia de un nuevo sujeto o una personalidad intelectual y literaria, diferenciada de su medio, sino que además un elemento reactivo que posibilitaría la definición (o su intento) de una personalidad social: la progresiva constitución de una identidad y de una imagen de cultura propia, asumida desde el descubrimiento y el contraste de la metrópolis europea con el interior del continente americano, que, más que paisaje, ahora es una condición social y política.

Esa misma situación anterior, sería uno de los puntos que se sometió al debate entre modernistas y antimodernistas, pero en todo caso, dio materia suficiente para que se crearan y fueran diseñándose las bases del rol de un artista en el contexto hispanoamericano, con experiencias iniciales tan diversas como las vividas por el mismo Darío, José Martí, José Enrique Rodó, Leopoldo Lugones o Gabriela Mistral. 


\section{Sincronía de formas plurales}

Seguir los trazos que el modernismo impuso en el espacio literario, implica recoger (y sorprenderse) que su expresión misma es dinámica. Poseyó una suerte de ubicuidad, pues incluso superando las dificultades de distancias y de desarrollo cultural en el ámbito hispanoamericano, de modo simultáneo casi, se comenzaron a dar a conocer escritores con el espíritu nuevo, estableciéndose una suerte de red por una geografía dispersa. Hablamos de Buenos Aires, La Habana, Santiago de Chile, Ciudad de México, Bogotá, Montevideo, Lima, para citar en términos generales, sin olvidar que el impulsor más visible partió desde su Nicaragua natal y que irradió por Centroamérica en viajes sucesivos.

Lo anterior es interesante de examinar, si pensamos que la confirmación de las nacionalidades no era un hecho tan lejano en el tiempo, por lo cual de algún modo opera un rango de fraternidad, al no haberse explicitado tan fuertemente el proceso de diferenciación entre países. En otro sentido, el alcance que pudo haber tenido la definitiva decadencia en España, cuya manifestación última fue su crisis interna y la guerra perdida con Estados Unidos (1898). En último término, el “horizonte cultural" que en la visión de Ángel Rama había conducido a la "autonomía literaria del continente" ${ }^{\prime 2}$, en gran medida favoreció que, al producirse una modificación respecto del modelo cultural español o su escasa referencia (Francia ahora es capital, es moderna), el sentido de la unificación se hiciera continental; es decir, no obstante las nacionalidades, se produjo un encuentro, pero no a través de una vía social, sino estética, literaria o cultural en último término.

Cuando hablamos de sincronía de formas plurales, constatamos entonces en primera instancia, las distintas posibilidades geográficas del modernismo, ocurridas uniformemente a partir de la década de 80-90 del siglo XIX. No obstante, en esa sincronía también emergen tonalidades literarias y poéticas, intenciones y compromisos explícitos sobre el oficio literario y la función del escritor, donde cada autor elige y experimenta los medios expresivos que le son más apropiados, por lo tanto, esa sincronía se mueve y no se constituye sobre la base de un paradigma que lo estabilice. Paradojalmente, el modernismo se consolida como movimiento literario entregando una visión de mundo, un periodo con una sensibilidad y un lenguaje que le es propio y que se diferencia de otros.

En términos generales, de las formas expresivas creadas o asimiladas por los modernistas, es indudable la huella de la poesía francesa, por

2 Ver de Ángel Rama su trabajo "Autonomía literaria americana", en La crítica de la cultura en América Latina, (1985), Caracas: Ayacucho. 
actitud, sensibilidad, el trazo de lo imaginario-poético. Pensamos en Baudelaire, Verlaine, Hugo, Rimbaud. Pero también está Poe y Whitman, la poesía clásica y la mitología, que sustentan gran parte de la creación literaria de los poetas y narradores, incluso en el ensayo como manifestación literaria (Rodó por ejemplo), la poesía y el arte oriental como modelo (japonés por ejemplo), introducido por Julián del Casal.

Según lo señalado, el modernismo fue creando una literatura tipificada por la sensualidad, la melodía y el cromatismo idiomático, formas métricas diversas y la experiencia del verso libre o blanco, la recuperación de palabras o los neologismos, la recodificación de mitos universales e incluso americanos, "[s]e explotaron zonas del sentimiento que hasta entonces habían sido tabú y llevaron a un primer término el diálogo entre sensualidad y sentimiento religioso que constituye una antinomia de la existencia humana..." (Franco, 1971:45), es decir, produjeron una suerte de desafío a lo convencional en términos literarios y, en muchos casos, en el ámbito de la moral personal, con juegos ambiguos o abiertamente rupturistas.

Todo este caos literario se logra uniformar mediante la observación de la imagen reductora del yo poético, que es el centro del discurso. En extremo, la síntesis de la sensibilidad modernista, generada desde ciertas condiciones históricas y culturales, opera mediante ese eje discursivo que se (auto)legitima como algo único y donde la misma expresión literaria es singular. La obra es derecho y revés de una identidad y una liberación emotiva, es lo distinto, y esto ocurre porque existe un yo (el artista) que diseña objetos artísticos en una sintaxis personal, que intenta la forma y el equilibrio perfecto entre el sonido y el sentido.

Más que sensibilidad, modelos literarios, motivos o temas, sincretismo y equilibrio formal, (des)sacralización de la realidad y encuentro con lo mítico, el modernismo fue configurando una perspectiva, una mirada sobre la realidad, una mirada que parte de la subjetividad sobre lo real, de ahí que ese Yo literario que mencionamos contenga esa realidad literaria, a la par que al resolverse en el texto, también haya experimentado el mismo proceso de simbolización referido a la contingencia de lo real:

¡Torres de Dios! ¡Poetas!

¡Pararrayos celestes

que resistís las duras tempestades,

como crestas escuetas,

como picos agrestes,

rompeolas de las eternidades!

(Darío, Canto de vida y esperanza, Texto IX) 
La identidad poeta-yo poético-torres de Dios, sitúa en un espacio de privilegio del autor real e imaginario del discurso poético, y allí reconocemos la raíz romántica y simbólica en el diseño de tal imagen y analogía. De todos modos, ese anhelo de integración de formas y de lenguajes sintetizándose en una figura central y protagónica, apunta a distinguir un temple de ánimo que recorre la mayoría de la literatura modernista, incluida la obra tan diversa y variada de un Martí y un Rodó, quienes reflexionaron sobre arte, sociedad, cultura y propuestas que interpretan críticamente la cultura en América.

\section{La (in)definición del modernismo}

Desde su origen periférico, con un pasado donde se habían constituido las bases del discurso cultural y literario, el modernismo emerge en las décadas finales de los ochenta del siglo XIX, en un contexto donde su presencia es un signo más de un momento de crisis y de polémicas; ahora, el antiguo escritor político, debe asumir que hay un sujeto que también discute, porque es su espacio de acción, esto es, el intelectual y el artista, los hombres que por antonomasia se dedican a hacer y a influir culturalmente, una figura nueva derivada de los cambios de fines de siglo.

Un aspecto que debemos mencionar se refiere a una variable en apariencia secundaria, pero que se proyectará más allá de una materia a discutir: la reflexión acerca del lenguaje. De hecho, para los autores de nuestro tema, el asunto no se redujo al simple hecho de valorizar o no el idioma castellano, por ejemplo, su estatuto oficial o su pureza, sino que en particular esto se vio pensando en función de la capacidad estética o expresiva de las palabras.

Con ese punto de vista, la búsqueda modernista -y su desafío a la larga- era conformar otros medios o modos de decir, dada la rigidez a que se había llegado, especialmente en la reiteración de lugares comunes en el uso idiomático y también literario. Rubén Darío atacó en tal sentido el peso de la tradición, afincada en América, por influencia, es claro, de España.

El relieve que adquirió la discusión sobre el idioma, en la perspectiva de un proceso cultural, en gran medida perdió intensidad, se desdibujó en medio de conflictos de orden económico y, cuestión más seria, de convivencia y aceptación de los otros, cuya resolución en algunos casos fue simplemente un conflicto entre naciones o la inestabilidad política.

Desde esa condición de origen, los escritores modernistas, esto es, aquellos que se definen en lo actual como necesidad y actitud, constru- 
yen su estética, que de un modo u otro, intenta resumir y sintetizar lo moderno mediante la experiencia literaria y vital, donde la textualidad fue la vida en la ciudad, también el cuerpo, la vida interior y las palabras que se plantean como desafío para expresar su pleno sentido. Así, hay una tensión entre lo que es el texto literario como construcción de lenguaje y de mundo, versus la constitución social fragmentada, que intenta de todos modos una especie de unidad espiritual.

En función de lo anterior, el mencionado absoluto de Darío será un elemento constitutivo de una perspectiva para problematizar(se), en la medida que fue una propuesta pública que identificó su poética, esto es, la búsqueda de recursos técnicos que expresen en rigor lo que intencionalmente se desea decir y que, en la práctica, también fue asimilada por otros escritores del momento.

La observación crítica que surge de lo anterior resulta del examen que pudiera hacerse sobre la idea de movimiento literario, que en rigor, perfila desde cierto ángulo la lectura de una obra o un conjunto de ellas, cuestión que no fue evitable por los escritores que se adscribieron a la propuesta de Darío. En concreto, la definición interior de "el movimiento de libertad que me tocó iniciar en América" dice Darío en 1905, excede lo literario; en ese ámbito, su eventual ordenamiento como línea programática fue negada por él mismo, y en gran medida no es del todo irrelevante que haya pensado así, considerando la búsqueda de coherencia con su propia actitud intelectual, que le llevó a resistir a una solicitud de "voces insinuantes": la escritura de un manifiesto, según leemos en las páginas introductorias a Prosas Profanas 1896. Visto así, el desarrollo de ideas que sintetice las propuestas del modernismo en un documento fundacional, a modo de los manifiestos poéticos del siglo XX, puede ser elaborado desde una estrategia argumentativa de negación.

A pesar de todo, existió el sentido de la pertenencia, de una comunidad de escritores comprometidos con su oficio (fueron hombres de letras) y su entorno social; Rodó, por ejemplo, al afirmar que era un modernista, enfatiza al decir: "yo pertenezco con toda mi alma a la gran reacción que da carácter y sentido a la evolución del pensamiento en las postrimerías de este siglo; a la reacción que, partiendo del naturalismo literario y positivismo filosófico las conduce, sin desvirtuarlos en lo que tienen de fecundos a disolverse en concepciones más altas" (Rodó, citado por Jiménez, 1992: 16-17).

La puesta en ejercicio de un diseño literario como algo consciente, su apertura hacia la sociedad con la visión de lo nuevo, el nuevo espíritu de Darío, parte entonces de un ideario, que al insertarse en el idioma y en nuestra realidad, produce un efecto de contraste, en el que la obra 
escapa a la sobredeterminación naturalista, en la medida que es una liberación de la forma, ejercicio poético superior, mirada interior a las sensaciones. En otro sentido, esa textualidad es el horror del mundo, la separación o el aislamiento del sujeto real y de enunciación, un modo de (auto)fragmentarse de la sociedad.

Lo que queda de naturalismo o positivismo, en la perspectiva actual, será ese impulso de actualidad, la disidencia frente al acomodo estatuido, con las condiciones de su supuesto progreso. No obstante, en el ámbito de la recepción lo que se produjo, además de una forma literaria, fue nuestra inserción a un modelo de sociedad con el cual se confrontaba; en la expresión cultural, la textualidad se transformó en fragmentos de mundo, el texto se abrió desde su absoluto de lenguaje y belleza a una moda literaria, finalmente, ese mismo texto como fragmento de un todo se transformó, también, en un signo de lo dispar en que se manifiesta la llamada Modernidad.

En Corriente alterna (1967) y Los hijos del limo (1974), Octavio Paz dirá que nuestra entrada al mundo moderno -aunque tardía-, se inicia con el modernismo, mundo cuya visión centrada de la cultura y fragmentación/ simultaneidad del tiempo lineal, desplegado en un espacio literario que se conjuga, son marcas que se aproximan y nos hacen contemporáneos de París, la capital poética y artística del siglo XIX. América, en la intención de Darío y sus seguidores, se hace cosmopolita, es decir, pertenece a un espacio, luego, a un tiempo, donde la lejanía ha sido rota, síntesis de ruptura con lo propio y acercamiento a una realidad diversa y plural como lo fue el movimiento mismo.

La (in)definición del modernismo, según vemos, manifiesta distintas modalidades o puntos de vista en su examen, pero en cualquier caso, resitúa el alcance que este tuvo, con una proyección que supera el umbral demarcatorio de las generaciones, en tanto que, desde una perspectiva cultural y de proceso literario, permite también redefinir la articulación que va desde el modelo modernista a la vanguardia, no sólo con sus alcances temáticos, sino por su reflexión sobre el lenguaje estético y la obra como signo.

\section{La obra como objeto artístico: prefiguraciones de la vanguardia}

Si consideramos la producción literaria de los autores modernistas, es posible advertir que, en muchos casos las notas prologales o los textos propiamente tales, manifiestan un discurso teórico e incluso crítico, refe- 
rido al oficio literario o al proceso constitutivo de una poética personal. La forma reflexiva y de desarrollo de ideas se traspasa e invade los géneros, lo que posibilita la identificación de los procesos individuales, asimismo el grado de coherencia, entre la teoría y la práctica, la desestimación de la imagen, donde el modernismo sólo sería expresividad y lirismo grandilocuente.

La especificidad del artista y de su obra, asumida como un oficio o una práctica consciente, creemos que es un logro importante y en ese campo, en verdad, el modernismo dejó su herencia. Los escritores de ese movimiento tuvieron la claridad suficiente para discutir y hacerse disidentes de su tradición más inmediata, pero también fueron capaces de responder con la invención de propuestas que, aunque tomadas desde otros contextos, al sobreponerlas en idioma castellano, se obtuvo una literatura que sería capaz de enfrentar nuevos proyectos socioculturales, es decir, el diseño de una tradición.

Sobre la base de estas propuestas, es que durante el modernismo la literatura se multiplicó en formas expresivas, pero el hecho singular de la escritura y el texto transformaron las palabras y su sentido en signo de lo artístico, la palabra-arte equivaldría a una señal de belleza. El problema que debieron resolver fue el encuentro del vocablo, la imagen, la metáfora, el adjetivo, en síntesis cómo lograr el verso, la estrofa, el poema, el ensayo y la crítica. No es extraño, por lo tanto, que en ese momento se haya manifestado una especie de verbalismo desmesurado, una sobrecarga de recursos literarios, la fusión de códigos de la pintura y la música traspasados a la palabra escrita, el sentido del ritmo y de los objetos que responden al criterio estético de la ornamentación de los espacios. Aparecen los símbolos. Con esto, decimos que en verdad la supuesta inspiración de raíz romántica (las Musas) equivalen más bien a una impostura, un juego o una invención fantástica, pues en este contexto la espontaneidad ha pasado a un nivel secundarísimo.

En ese proceso de experimentación con lo formal, agregamos, se produjeron verdaderos hallazgos literarios, consciente o inconscientemente, de modo que "después de esa experiencia [del modernismo] el castellano pudo soportar pruebas más rudas y aventuras más peligrosas. Entendido como lo que realmente fue -un movimiento cuyo fundamento y meta primordial era el movimiento mismo- aún no termina..." (Paz, 1976: 12). La concepción de la obra como objeto artístico, en la perspectiva que seguimos, establece en muchos sentidos la idea de un producto, una especie de operatoria formal para generar una curiosidad literaria, lo cual acerca a sus autores a procedimientos de diseño propios de la vanguardia, en tanto se experimenta con el lenguaje, sólo que sin llegar todavía a la mutación de la sintaxis. 
En el "Himno de la torres" de Leopoldo Lugones, perteneciente a Las montañas de oro (1897), encontramos:

Canto: la altas torres, gloria del siglo y decoro del suelo. Las torres que ven las distancias: las torres que cantan la gloria de las buenas artes del hierro y de la piedra. Las torres gigantes que tienen cien lenguas intactas (Lugones, Las montañas de oro)

Leído hoy, es un texto que [a]parece como contemporáneo, adscrito a la estética de seriaciones generadas por el futurismo y el creacionismo a comienzos de siglo, con su carga de miradas múltiples sobre un mismo objeto. Lunario sentimental (1909) es superior en creatividad y allí plantea su poética vanguardista.

Con igual fuerza y notoria afinidad, en El rosario de Eros (1924) de Delmira Agustini, publicado en sus Obras completas, leemos:

Hay cabeza doradas al sol, como maduras...

Hay cabezas tocadas de sombra y de misterio, cabezas coronadas de una espina invisible, cabezas que sonrosa la rosa del ensueño, cabezas que se doblan a cojines de abismo, cabezas que quisieran descansar en el cielo, algunas que no alcanzan a oler a primavera, y muchas que trascienden a flores de invierno... (Agustini, El rosario de eros)

En este caso, según vemos, la disposición estrófica, las imágenes y el lenguaje evocan componentes oníricos, además del caos temático cuyo creciente desarrollo mantiene un centro a partir de la reiteración anafórica.

En esa disposición, es destacable además cómo el verso logra autonomía, rompiendo de ese modo la tendencia modernista a desarrollar el poema desde la retórica del tema, que en este caso se reconstruye en asociaciones libres y enumeraciones o series. Avanzado el poema, se dice

Hay manos que nacieron con guantes de caricia, manos que están colmadas de de la flor del deseo, manos en que se siente un puñal nunca visto, manos en que se ve un intangible cetro; pálidas o morenas, voluptuosas o fuertes, en todas, todas ellas puede engarzar un sueño ... 


\begin{abstract}
¡Ah, entre todas las manos yo he buscado tus manos!
Tu boca entre las bocas, tu cuerpo entre los cuerpos,

de todas las cabezas yo quiero tu cabeza,

de todos esos ojos, tus ojos solos quiero.

Tú eres el más triste, por ser el más querido,

tú has llegado el primero por venir de más lejos ...

(Agustini, El rosario de eros)
\end{abstract}

Según puede verse, el desarrollo adoptado por Agustini, expresa ahora, contrastivamente, un fondo temático que evoca los motivos del amor pasional y único del romanticismo, con las técnicas y rasgos estéticos de avanzada; la elección del amado entre otros posibles, el tono exaltado, junto a versos que manifiestan imágenes fracturadas de la realidad, cuyo ensamble parte del lugar en que se sitúa el yo poético: el tono íntimo y confesional.

Se puede afirmar entonces que, en el caso de los poetas usados a modo de ejemplo (sin olvidar otros posibles como Julio Herrera y José Juan Tablada entre otros), ha operado un procedimiento propio de la poesía contemporánea, esto es, el vaciamiento del yo, para instalar en su lugar los objetos y el lenguaje que los nomina; se ha experimentado con la forma y el espacio poético a partir de denominaciones y determinaciones gramaticales que posibilitan la gracia de inventar imágenes nuevas, una realidad sustentada en el lenguaje mismo, sin exterioridad, lo cual llegará al máximo, pero en la situación de las vanguardias posteriores. Es el momento en que ha estallado la realidad y el lenguaje con la primera guerra en Europa; en Hispanoamérica, surgirán las vanguardias, múltiples y paradojales, en las décadas iniciales del siglo XX, donde se hará uso de la apropiación cultural iniciándose una nueva época en nuestra historia literaria.

\title{
6. Conclusiones
}

Las variaciones temáticas y de análisis global sobre el modernismo, ponen en evidencia las tensiones a que estuvo sometido, entendiendo con esto que, en verdad, esas complicaciones fueron experimentadas y vividas por quienes impulsaron los complejos cambios literarios y culturales de fines del siglo XIX y comienzos del XX.

En el modernismo se entrecruzan variables que entran en conflicto con lo estatuido, de modo que, inevitablemente, aparece una teoría sobre el arte y la sociedad de modo simultáneo, cuya práctica pone en cuestión la efectividad de los discursos. Así, la idea de proceso con que abordamos el trabajo, da cuenta con ese sentido de la distintas direccio- 
nes y perspectivas con que se recepcionó el movimiento, a la vez pone en dinámica el valor canonizado de su importancia y que, al contrastarlo desde hoy, legitima el significado de esa tradición literaria.

Así, es posible descubrir la originalidad de las propuestas, al mismo tiempo que su heterogeneidad, o la "resistencia a la teoría" que uniformara el proyecto; de algún modo, es una marca anticipadora y un desafío para comprender nuestra Modernidad que (des)legitima su propio pasado.

Nuestro interés, en tal sentido, ha sido poner en discusión, en el ámbito literario y cultural, una especie de resemantización o reubicación del lugar común del modernismo, que después de todo, por los ejemplos presentados, marca un giro cultural y de lenguaje a comienzos del siglo $\mathrm{XX}$.

\section{Bibliografía}

\section{Autores}

Agustini, D. (1971). Poesías completas. Barcelona: Labor.

Darío, R. $(1896 ; 1971)$. Prosas profanas. Buenos Aires: Edicom.

(1905; 1967). Cantos de vida y esperanza. Buenos Aires: Centro editor de América Latina.

(1888; 1953). Azul. Santiago de Chile: Zigzag.

Lugones, L. (1982). Antología poética. Madrid: Alianza. Prólogo: Jorge Luis Borges.

Jiménez, J. (1992).

Antología crítica de la poesía modernista hispanoamericana, Madrid, Hiperión.

\section{Estudios literarios}

Franco, J. (1971).

La cultura moderna en América latina. México: Joaquín Mortiz.

Friedrich, H. (1974). Estructura de la lírica moderna. Barcelona: Seix Barral.

Gutiérrez Girardot, R. (1987). El modernismo. Supuestos históricos y culturales. México: FCE

Henríquez Ureña, M. (1954). Breve historia del modernismo. México: FCE. 
Henríquez Ureña, P. (1949). Las corrientes literarias en la América hispánica. México: FCE.

Lezama Lima, J. (1969). L L expresión americana. Madrid: Alianza editorial.

Martí, J. (1970).

Nuestra América. Barcelona: Eds. Ariel.

Paz, O. $(1965 ; 1971)$.

"El caracol y la sirena", en Cuadrivio. México: Joaquín Mortiz.

(1967; 1970). Corriente alterna. México: Siglo XXI.

(1974; 1981). L L L L L hijos del limo. Barcelona: Seix Barral.

Pizarro, A. (1994). De ostras y caníbales. Santiago de Chile: Eds. Editorial U. de Santiago.

Rama, A. (1985).

"Autonomía literaria americana" en Crítica de la cultura latinoamericana, Caracas, Ayacucho, original de Prólogo de Clásicos hispanoamericanos, Vol. I, Siglo XIX Barcelona, Círculo de lectores, 1983

Rodríguez, M. (1967). El modernismo en Chile y en Hispanoamérica. Santiago: Universitaria. 